\title{
Concordance analysis of methylation biomarkers detection in self-collected and physician-collected samples in cervical neoplasm
}

\author{
Cheng-Chang Chang ${ }^{1,2}$, Rui-Lan Huang ${ }^{3}$, Yu-Ping Liao ${ }^{4}$, Po-Hsuan Su', Yaw-Wen Hsu' ${ }^{5}$, Hui-Chen Wang ${ }^{4}$,
} Chau-Yang Tien ${ }^{1}$, Mu-Hsien Yư ${ }^{1}$, Ya-Wen Lin ${ }^{6}$ and Hung-Cheng Lai ${ }^{2,3,7^{*}}$

\begin{abstract}
Background: Non-attendance at gynecological clinics is a major limitation of cervical cancer screening and self-collection of samples may improve this situation. Although HPV testing of self-collected vaginal samples is acceptable, the specificity is inadequate. The current focus is increasing self-collection of vaginal samples to minimize clinic visits. In this study, we analyzed the concordance and clinical performance of DNA methylation biomarker (PAX1, SOX1, and ZNF582) detection in self-collected vaginal samples and physician-collected cervical samples for the identification of cervical neoplasm.
\end{abstract}

Methods: We enrolled 136 cases with paired methylation data identified from abnormal Pap smears $(n=126)$ and normal controls $(n=10)$ regardless of HPV status at gynecological clinics. The study group comprised 37 cervical intraepithelial neoplasm I (CIN1), 23 cervical intraepithelial neoplasm II (CIN2), 16 cervical intraepithelial neoplasm III (CIN3), 30 carcinoma in situ (CIS), 13 squamous cell carcinomas (SCCs) and seven adenocarcinomas (ACs)/adenosquamous carcinomas (ASCs). PAX1, SOX1 and ZNF582 methylation in study samples was assessed by real-time quantitative methylation-specific polymerase chain reaction analysis. We generated methylation index cutoff values for the detection of CIN3+ in physician-collected cervical samples for analysis of the self-collected group. Concordance between the physician-collected and self-collected groups was evaluated by Cohen's Kappa. Sensitivity, specificity and area under curve (AUC) were calculated for detection of CIN3+ lesions. Finally, we produced an optimal cutoff value with the best sensitivity from the self-collected groups.

Results: We generated a methylation index cutoff value from physician-collected samples for detection of CIN3+. There were no significant differences in sensitivity, specificity of PAX1, SOX1 and ZNF582 between the self-collected and physician-collected groups. The methylation status of all three genes in the normal control samples, and the CIN 1 , CIN2, CIN3, CIS, ACs/ASCs and SCC samples showed reasonable to good concordance between the two groups $(\mathrm{K}=0.443,0.427$, and 0.609 for PAX1, SOX1, and ZNF582, respectively). In determining the optimal cutoff values from the self-collected group, ZNF582 showed the highest sensitivity $(0.77 ; 95 \% \mathrm{Cl}, 0.65-0.87)$ using a cutoff value of 0.0204 .

Conclusions: Methylation biomarker analysis of the three genes for detection of CIN3+ lesions shows reasonable to good concordance between the self-collected and physician-collected samples. Therefore, self-collection of samples could be adopted to decrease non-attendance and improve cervical screening.

Keywords: Cervical cancer, DNA methylation, Biomarker, Self-collected, Physician-collected, Real-time quantitative methylation-specific polymerase chain reaction (QMSP)

\footnotetext{
* Correspondence: hclai30656@gmail.com

${ }^{2}$ Graduate Institute of Medical Sciences, National Defense Medical Center,

Taipei, Taiwan, Republic of China

${ }^{3}$ Department of Obstetrics and Gynecology, Shuang Ho Hospital, Taipei

Medical University, Taipei, Taiwan, Republic of China

Full list of author information is available at the end of the article
}

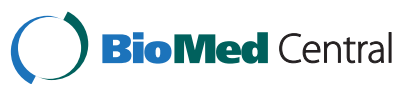

(c) 2015 Chang et al.; licensee BioMed Central. This is an Open Access article distributed under the terms of the Creative Commons Attribution License (http://creativecommons.org/licenses/by/4.0), which permits unrestricted use, distribution, and reproduction in any medium, provided the original work is properly credited. The Creative Commons Public Domain Dedication waiver (http://creativecommons.org/publicdomain/zero/1.0/) applies to the data made available in this article unless otherwise stated. 


\section{Background}

Cervical cancer remains one of the main causes of death from cancer among women worldwide [1]. Cytologybased screening has successfully reduced mortality associated with cervical cancer [2]. However, the majority of cases of cervical cancer are still associated with absent or deficient screening. In previous studies, approximately $50 \%$ of cervical cancers were diagnosed in women who were not screened $[3,4]$. Complete participation would achieve a greater improvement in screening effectiveness than intensifying screening policies [3]. Therefore, it is important to improve participation rates among women with a history of non-attendance.

Epidemiological studies have emphasized that human papillomaviruses (HPVs) are the main etiological factor for cervical cancer and that these viruses are present in almost all cervical cancer tissues [5]. Screening participation rates for cervical cancer can be improved by offering non-attending women the tools to collect a vaginal sample at home. Self-collection is an acceptable method to potentially increase participation [6]. Studies have demonstrated that self-collected samples are suitable for HPV DNA testing and can increase participation rates in primary screening for cervical cancer [6-11]. However, women whose self-collected specimens test positive for high-risk HPV (hrHPV) require additional triage testing because the specificity of assays for hrHPV is insufficient to justify direct referral for colposcopy in all cases $[11,12]$. Although cytology is an accepted and standard method of examination in triage for hrHPVpositive women [13], cytological testing of self-collected samples does not yield reliable results and a visit to a physician is required [14].

In normal, precancerous and cervical cancer tissues, the DNA methylation profiles of the host genome may indicate tissue-specific perturbations that occur during carcinogenesis [15]. DNA methylation leaves a heritable record of such interactions and is an ideal biomarker for cancer detection [16-20], which could be used to triage possible cases of cervical cancer [21-24]. Previously, we used a CpG island microarray approach to identify novel genes that were silenced by methylation in cervical squamous cell carcinoma (SCC) [25]. Quantitative analysis of the PAX1 and SOX1 genes can be used effectively for detection of cases of CIN that are grade 3 or worse (CIN3+) [17]. Using methylated DNA sequence immunoprecipitation coupled with microarray analysis to identify other genes with clinical applications, we found that the gene for zinc finger protein 582 (ZNF582) was highly methylated in SCC [18]. This gene is also highly methylated in adenocarcinoma (AC) of the cervix [26]. In Taiwanese Gynecologic Oncology Group (TGOG) studies, we used a methylation biomarker and hrHPV tests to detect CIN3+ lesions in low grade squamous intraepithelial lesions (LSIL). ZNF582 methylation is implicated as a promising biomarker for use in the positive triage of cytological diagnoses of low grade squamous intraepithelial lesions [27]. Combined parallel testing using Pap smears and PAX1 or SOX1 methylation tests may provide better performance than a combination of Pap smears with HPVtesting in detection of cervical neoplasm [28]. The clinical performance of PAX1, SOX1, and ZNF582 as biomarkers of cervical neoplasm has been validated in multi-center clinical trials; therefore, analysis of changes in the methylation status of these genes could be applied for selfcollected vaginal samples.

The aim of this study was to validate the concordance and clinical performance of PAX1,SOX1, and ZNF582 methylation for detection of CIN3+ lesions in selfcollected and physician-collected vaginal samples. Our hope is that these genes will serve as sensitive methylation biomarkers for clinical cervical cancer screening of self-collected samples.

\section{Methods}

\section{Patients and sampling}

The flowchart illustrating the study design is shown in Fig. 1. We randomly selected a sample set from women attending our gynecologic outpatient department. All women used a cytobrush (CooperSurgical, CT, USA) to collect a vaginal sample as instructed by a physician. Subsequently, a physician-collected cervical sample was obtained.

Patients with normal cervixes $(\mathrm{n}=10)$, and those with CIN1 ( $\mathrm{n}=37)$, CIN2 ( $\mathrm{n}=23)$, CIN3 $(\mathrm{n}=16)$, carcinoma in situ (CIS) $(\mathrm{n}=30), \mathrm{SCC}(\mathrm{n}=13)$, and adenocarcinoma (AC)/adenosquamous carcinoma (ASC) $(n=7)$ of the uterine cervix participated in this study. Patients whose cervical samples had normal cytology served as control subjects. The patients were diagnosed, treated, and had their tissues banked at the National Defense Medical Center, Taipei, Taiwan as described [29]. All CINs and invasive cancers were confirmed by histopathology. Control patients were recruited from healthy women who underwent routine Pap screening during the same period. Exclusion criteria included pregnancy, chronic or acute systemic viral infections, a history of cervical neoplasm, skin or genital warts, an immunocompromised state, presence of other cancers, and previous surgery of the uterine cervix.

\section{Generation of methylation index cutoff values and clinical accuracy calculation}

Real-time quantitative methylation-specific polymerase chain reaction (QMSP) was performed to assess the methylation status of PAX1, SOX1 and ZNF582 in study samples. We generated methylation index cutoff values from physician-collected cervical samples for detection of 


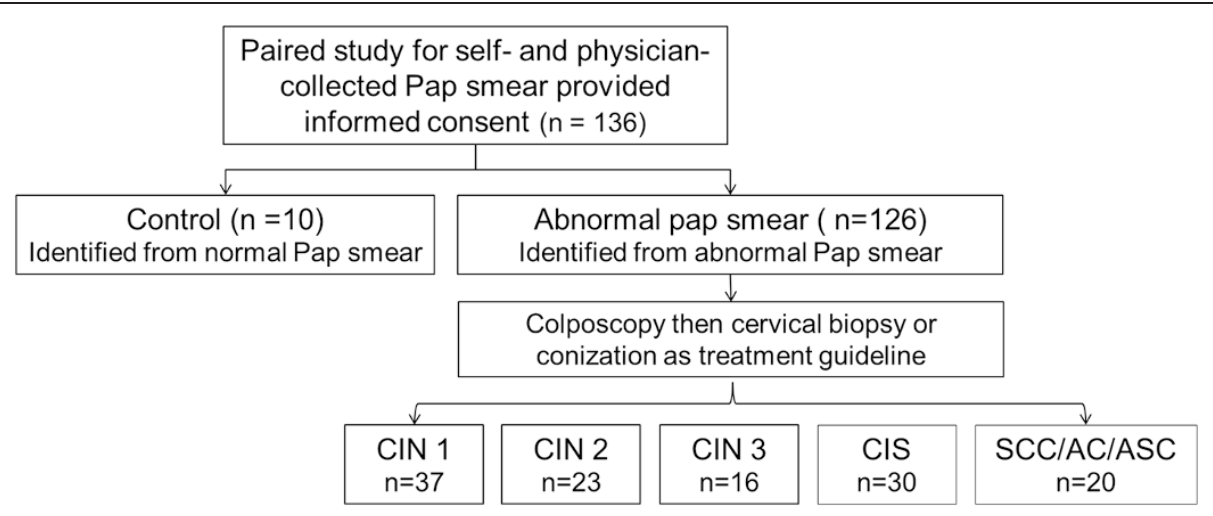

Fig. 1 The study design flowchart. All women used a cytobrush (CooperSurgical, CT, USA) to collect a vaginal sample as instructed by a physician. Subsequently, a physician-collected cervical sample was obtained. Patients with abnormal Pap smear results were managed by colposcopy followed by cervical biopsy or conization according to treatment guidelines. (CIN: cervical intraepithelial neoplasm, CIS: carcinoma in situ, SCC: squamous cell carcinoma, AC: adenocarcinoma, ASC: adenosquamous carcinoma)

CIN3+ in self-collected samples. Sensitivity, specificity and area under curve (AUC) were calculated for detection of CIN3+ lesions. Finally, we produced an optimal cutoff value with the best sensitivity from the self-collected groups.

\section{Real-time quantitative methylation-specific polymerase chain reaction amplification of DNA}

Genomic DNA was extracted from the collected specimens using a protocol established for tissue banking. The concentration of DNA was determined using the Nanodrop 1000 (Thermo Fisher Scientific). QMSP was performed after bisulfite treatment of denatured genomic DNA. Gene symbols, primers, and probes for QMSP are available on request [17]. The COL2A gene was used as an internal reference to adjust the amount of input DNA by amplifying non-CpG sequences in each sample. QMSP was performed with a TaqMan probe system in a Roche LightCycler 480 system. The $5^{\prime}$ and $3^{\prime}$ ends of the probes were labeled with 6-carboxy-fluorescein (6-FAM) and a quencher dye, respectively. The $20 \mu \mathrm{L}$ reaction mix contained $2 \mu \mathrm{L}$ of bisulfite template DNA $(2 \mu \mathrm{L})$, primers ( $250 \mathrm{nM}$ each), TaqMan probe $(225 \mathrm{nM})$, and FastStart Universal Probe Master $(10 \mu \mathrm{L})$ (ROX, Roche). For the TaqMan-based QMSP, each sample was analyzed in duplicate. The reactions were performed by using an initial incubation at $95{ }^{\circ} \mathrm{C}$ for $10 \mathrm{~min}$, followed by 45 cycles of $95{ }^{\circ} \mathrm{C}$ for $15 \mathrm{~s}$ and annealing and extension at the appropriate temperatures for $1 \mathrm{~min}$. The level of DNA methylation was described as the methylation index (M-index) and calculated as follows: $10,000 \times 2^{[(\mathrm{Cp} \text { of } C O L 2 A)}-(\mathrm{Cp}$ of gene)] $[18]$. The QMSP was deemed to be a failure if the $\mathrm{Cp}$ value of COL2A was higher than 36.

\section{Ethics statement}

Informed consent to participation in this study was obtained from all patients and control subjects. This study was conducted in accordance with the guidelines, and with the approval of, the Ethics Committee of the Institutional Review Boards of the Tri-Service General Hospital, National Defense Medical Center (TSGHNDMCIRB-09605-090).

\section{Statistical analysis}

Data were analyzed using the updated MedCalc version 14. To determine the detection rate, CIN3 was taken as a cutoff value for the QMSP analysis of three genes in self-collected and physician-collected samples. The receiver operating characteristic (ROC) curve was used to select the optimal cutoff value according to the maxima of sensitivity and specificity to distinguish CIN3+ (including CIN3, CIS, SCC, AC and ASC) and $\mathrm{CIN}^{-}$(including normal controls, CIN1 and CIN2) patients [30]. The McNemar test was used to test the proportion of self-collected and physiciancollected samples in CIN3+ groups by the optimal cutoff value of physician-collected. The concordance between the self-collected and physician-collected samples was measured by Cohen's Kappa coefficient. Differences with $P$-values less than 0.05 were considered to indicate statistical significance.

\section{Results}

Population, study design flowchart and cytology/histology of study samples

We invited 136 women to participate in this study of self-collected samples with paired methylation data from samples of 10 normal control cervixes, 37 CIN1, 23 CIN2, 16 CIN3, 30 CIS, and 20 invasive cancers (13 SCCs and 7 ACs/ASCs) (Fig. 1). Details of the cytology/ histology and mean age of the subjects are shown in Table 1. 
Table 1 Cytology/histology and mean age of study participants

\begin{tabular}{lll}
\hline Diagnosis & $\begin{array}{l}\text { Cases } \\
(\mathrm{n})\end{array}$ & $\begin{array}{l}\text { Mean age } \pm \text { SD } \\
\text { (years) }\end{array}$ \\
\hline Total & 136 & $47.9 \pm 12.9$ \\
Normal cytology & 10 & $53.0 \pm 16.2$ \\
CIN1 & 37 & $43.3 \pm 11.3$ \\
CIN2 & 23 & $47.1 \pm 14.3$ \\
CIN3 & 16 & $48.1 \pm 12.5$ \\
CIS & 30 & $48.0 \pm 11.9$ \\
SCC & 13 & $54.2 \pm 11.6$ \\
AC/ASC & 7 & $57.1 \pm 14.9$ \\
\hline
\end{tabular}

SD Standard deviation, CIN1 cervical intraepithelial neoplasm type 1, CIN2 cervical intraepithelial neoplasm type 2, CIN3 cervical intraepithelial neoplasm type 3, CIS carcinoma in situ, SCC squamous cervical carcinoma, AC adenocarcinoma, ASC adenosquamous carcinoma

Validation of clinical performance and concordance analysis of methylation biomarkers in self-collected and physician-collected samples

We generated a methylation index cutoff value from physician-collected samples for detection of CIN3+ and then compared the methylation of PAX1,SOX1 and ZNF582 genes in physician-collected and self-collected samples. There were no significant differences in the sensitivity and specificity of the QMSP analysis of PAX1, SOX1, and ZNF582 between the self-collected and physician-collected samples (Table 2). In addition, the PAX1, SOX1, and ZNF582 methylation profiles in the CIN3+ positive cases among the self-collected samples were similar to those among the physician-collected samples (percentage positive among self-collected samples: $60.6 \%, 77.3 \%$, and $63.6 \%$, respectively; percentage positive among physician-collected samples: 64.64 \%, $74.24 \%$, and $60.61 \%$, respectively) ( $P=0.81,0.81$, and 0.81 , respectively; Table 2 ). Self-collection was found to be comparable with physician-collected samples for the detection of cervical methylation biomarkers $(\kappa=0.443$, 0.427 , and 0.609 for PAX1,SOX1, and ZNF582, respectively; Fig. 2).

\section{Optimization of the clinical accuracy of methylation biomarkers using the cutoff values of the self-collected group}

The clinical performance of QMSP of ZNF582 in the selfcollected group was better than that in the physiciancollected group using a cutoff value generated from the physician-collected group (sensitivity: 0.64; 95\%CI, 0.510.75 vs. $0.6195 \% \mathrm{CI}, 0.48-0.72$, specificity: 0.87 ; $95 \% \mathrm{CI}$, $0.77-0.94$ vs 0.83 ; $95 \% \mathrm{CI}, 0.72-0.91$; Table 2 ). Using a ROC curve to obtain the best cutoff values from the selfcollected group, we found that QMSP of ZNF582 had the highest sensitivity $(0.77 ; 95 \% \mathrm{CI}, 0.65-0.87)$ and specificity (0.77; 95\%CI, 0.66-0.86) (Table 3) at a cutoff value of
0.0204. There were no differences in the AUCs of PAX1 and SOX1 between the self-collected and physiciancollected groups ( 0.731 vs. $0.727, P=0.93$ and 0.752 vs. $0.764, P=0.80$, respectively, Fig. 3). The AUC of ZNF582 in the self-collected group showed significantly better clinical performance than that in the physician-collected group (0.830 vs. $0.747, P=0.04$; Fig. 3 ).

\section{Discussion}

Our data showed reasonable to good concordance in the DNA methylation the PAX1, SOX1, and ZNF582 genes for detection of CIN3+ lesions between self-collected vaginal samples and physician-collected cervical samples. These findings indicate that in the future, the requirement for patients to visit a physician for screening could be reduced by submitting self-collected samples. Compared with the current cytology-based call-recall programs, self-collected vaginal samples can increase access to cervical screening and may help to further reduce the incidence of cervical cancer by increasing the rate of participation in screening programs $[2,11]$.

Our study for the comparison of the concordance of methylation status between self-collected vaginal samples and physician-collected cervical samples was conducted in a relatively large sample-size. Self-collection was found to be comparable with physician-collected samples for the detection of cervical methylation biomarkers. This is consistent with other recent reports, which have also shown high concordance in the results of methylation analysis of self-sampled vaginal material and physician-collected cervical scrapes [31]. Furthermore, our study was conducted using a relatively large number of high-grade squamous intraepithelial neoplasm (HSIL, including CIN2, CIN3/CIS, SCC, AC/ ASC) samples, including seven cases of ACs/ASCs. In addition, assessment of the methylation biomarkers in ZNF582 provided the best clinical accuracy among selfcollected samples (AUC: 0.83; sensitivity, 0.77 (95\%CI, 0.65-0.87); specificity, 0.77 (95\%CI, 0.66-0.86), using a cutoff of 0.0204). These results are comparable with those of well-performed cytological testing, indicating that methylation biomarker analysis of self-collected vaginal samples has the potential for use in populationbased studies comparing the clinical performance of cytological testing for alternative methods of screening of cervical cancer.

The limitation of this study is the restricted sample set, especially in the normal controls, because we focused on investigating the concordance between physician-collected samples and self-collected samples obtained using a cytobrush. This device was designed for physician sampling and is not particularly practical for use in self-collection sampling. Consequently, the level of compliance and success in obtaining a sample using this method was low 
Table 2 Comparison the detection of $\mathrm{CIN3}^{+}$between the physician-collected and self-collected samples using methylation of PAX1, SOX1 and ZNF582 genes

\begin{tabular}{|c|c|c|c|c|c|c|c|c|c|c|}
\hline \multirow[t]{2}{*}{ Physician-collected } & \multirow[b]{2}{*}{$\begin{array}{l}\text { Cutoff } \\
\text { Point }^{a}\end{array}$} & \multirow[b]{2}{*}{$\begin{array}{l}\text { Positive case of CIN2- } \\
\text { (Total, } N=70)\end{array}$} & \multirow[b]{2}{*}{$\begin{array}{l}\text { Positive case of CIN3+ } \\
\text { (Total, } \mathrm{N}=66 \text { ) }\end{array}$} & \multirow[b]{2}{*}{$\begin{array}{l}\text { Sensitivity } \\
(95 \% \text { Cl) }\end{array}$} & \multirow[b]{2}{*}{$\begin{array}{l}\text { Specificity } \\
(95 \% \text { Cl) }\end{array}$} & \multicolumn{5}{|l|}{ Self-collected } \\
\hline & & & & & & $\begin{array}{l}\text { Positive in CIN2- } \\
\text { (Total } N=70)\end{array}$ & $\begin{array}{l}\text { Positive in CIN3+ } \\
\text { (Total } N=66)\end{array}$ & $\begin{array}{l}\text { Sensitivity } \\
(95 \% \text { Cl) }\end{array}$ & $\begin{array}{l}\text { Specificity } \\
(95 \% \text { Cl) }\end{array}$ & $P^{b}$ \\
\hline \multirow[t]{2}{*}{ PAX 1} & 0.014 & 16 & 42 & 0.64 & 0.77 & 17 & 40 & 0.61 & 0.76 & 0.81 \\
\hline & & $(22.86 \%)$ & $(64.64 \%)$ & (0.51 to 0.75 ) & (0.66 to 0.86$)$ & (24.3\%) & $(60.6 \%)$ & (0.48 to 0.72$)$ & (0.64 to 0.85 ) & \\
\hline \multirow[t]{2}{*}{ SOX1 } & 0.156 & 18 & 49 & 0.74 & 0.74 & 25 & 51 & 0.77 & 0.64 & 0.81 \\
\hline & & (25.71\%) & (74.24 \%) & (0.62 to 0.84$)$ & (0.62 to 0.84$)$ & (35.7\%) & (77.3\%) & (0.65 to 0.87$)$ & (0.52 to 0.75$)$ & \\
\hline \multirow[t]{2}{*}{ ZNF582 } & 0.214 & 12 & 40 & 0.61 & 0.83 & 9 & 42 & 0.64 & 0.87 & 0.81 \\
\hline & & (17.14 \%) & (60.61\%) & (0.48 to 0.72$)$ & (0.72 to 0.91$)$ & (12.9\%) & $(63.6 \%)$ & (0.51 to 0.75$)$ & (0.77 to 0.94$)$ & \\
\hline \multirow[t]{2}{*}{ Any of SOX1, PAX1 } & & 25 & 53 & 0.80 & 0.64 & 32 & 53 & 0.80 & 0.54 & 1.00 \\
\hline & & (35.71\%) & (80.3 \%) & (0.69 to 0.89 ) & (0.52 to 0.75$)$ & $(44.7 \%)$ & $(80.3 \%)$ & (0.69 to 0.89 ) & (0.42 to 0.66$)$ & \\
\hline \multirow[t]{2}{*}{ Any of SOX1, ZNF582 } & & 22 & 53 & 0.80 & 0.69 & 27 & 53 & 0.80 & 0.61 & 1.00 \\
\hline & & (31.4 \%) & (80.3 \%) & (0.69 to 0.89 ) & (0.56 to 0.79$)$ & $(38.6 \%)$ & $(80.3 \%)$ & (0.69 to 0.89 ) & (0.49 to 0.73 ) & \\
\hline \multirow[t]{2}{*}{ Any of PAX1, ZNF582 } & & 23 & 48 & 0.73 & 0.67 & 20 & 48 & 0.73 & 0.71 & 1.00 \\
\hline & & (32.9 \%) & (72.7 \%) & (0.60 to 0.83 ) & (0.55 to 0.78 ) & $(28.6 \%)$ & (72.7 \%) & (0.60 to 0.83 ) & (0.59 to 0.82 ) & \\
\hline \multirow[t]{2}{*}{ Any one of three } & & 29 & 57 & 0.86 & 0.59 & 34 & 55 & 0.83 & 0.51 & 0.75 \\
\hline & & (41.4 \%) & (86.4 \%) & (0.76 to 0.94 ) & (0.46 to 0.70 ) & $(48.6 \%)$ & $(83.3 \%)$ & (0.72 to 0.91$)$ & (0.39 to 0.64 ) & \\
\hline \multirow[t]{2}{*}{ Any two of three } & & 12 & 40 & 0.71 & 0.83 & 11 & 44 & 0.67 & 0.84 & 0.52 \\
\hline & & (17.1\%) & $(60.6 \%)$ & (0.48 to 0.72 ) & (0.72 to 0.91 ) & (15.7\%) & $(66.7 \%)$ & (0.5 to 0.78$)$ & (0.74 to 0.92 ) & \\
\hline
\end{tabular}

Cl confident interval

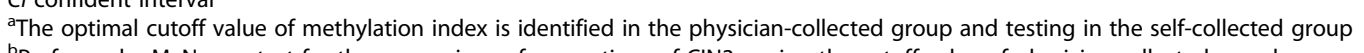

berformed a McNemar test for the comparison of proportions of CIN3+ using the cutoff value of physician-collected samples 


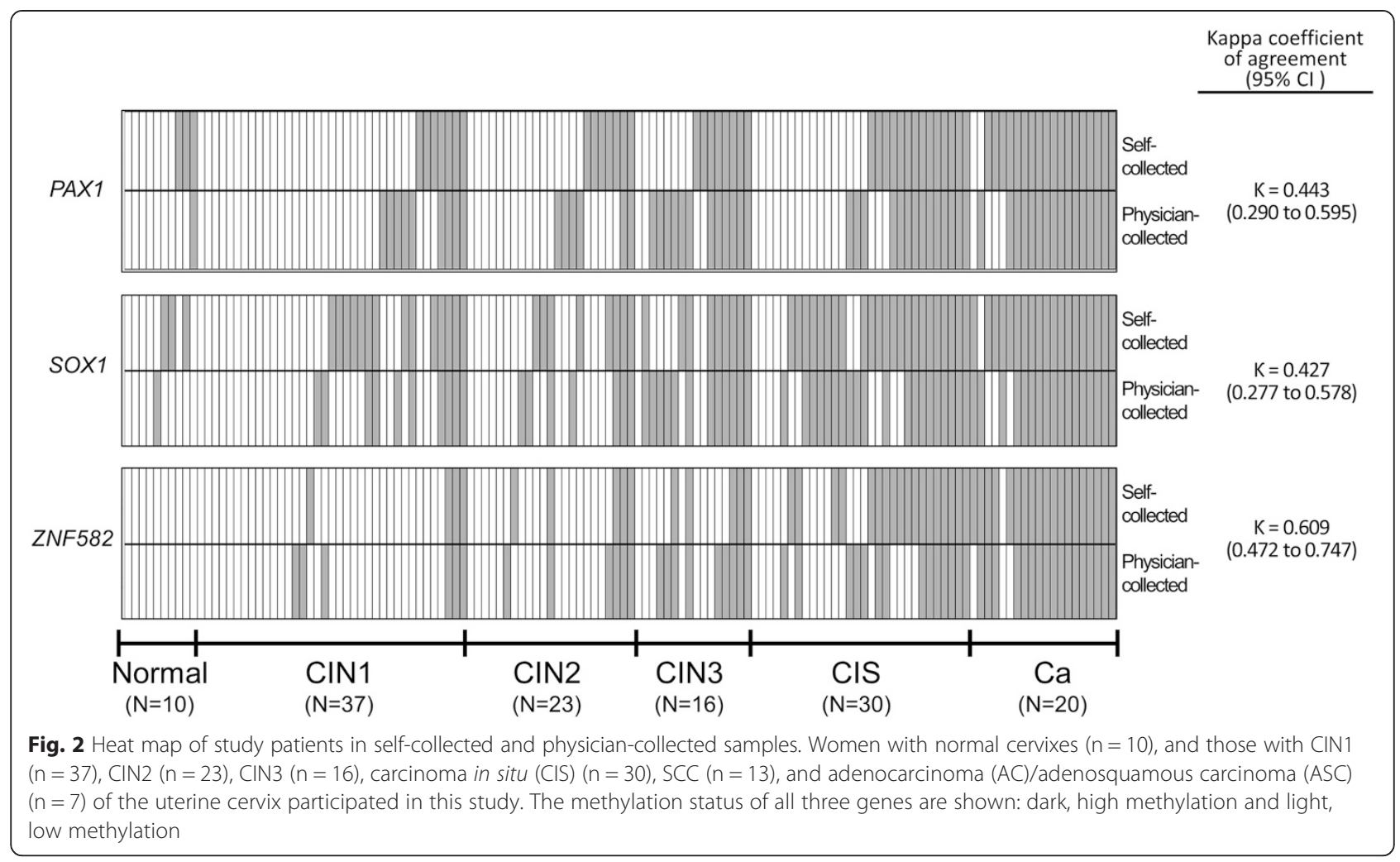

Table 3 The optional cutoff value generated from self-collected samples for detection of $\mathrm{CIN}^{+}$in self-collected samples with methylation of PAX1, SOX1 and ZNF582 genes

\begin{tabular}{|c|c|c|c|c|c|}
\hline & $\begin{array}{l}\text { Cutoff } \\
\text { Point }^{\mathrm{a}}\end{array}$ & $\begin{array}{l}\text { Positive cases of CIN2- } \\
\text { (Total, } N=70 \text { ) }\end{array}$ & $\begin{array}{l}\text { Positive cases of CIN3+ } \\
\text { (Total, } \mathrm{N}=66 \text { ) }\end{array}$ & $\begin{array}{l}\text { Sensitivity } \\
(95 \% \mathrm{Cl})\end{array}$ & $\begin{array}{l}\text { Specificity } \\
(95 \% \text { Cl) }\end{array}$ \\
\hline \multirow[t]{2}{*}{ PAX1 } & 0.0027 & 20 & 48 & 0.73 & 0.71 \\
\hline & & (28.6 \%) & (70.6 \%) & (0.60 to 0.83 ) & (0.60 to 0.82$)$ \\
\hline \multirow[t]{2}{*}{ SOX1 } & 0.516 & 18 & 48 & 0.73 & 0.74 \\
\hline & & (25.7\%) & (72.7 \%) & (0.60 to 0.83 ) & (0.62 to 0.84 ) \\
\hline \multirow[t]{2}{*}{ ZNF582 } & 0.0204 & 16 & 51 & 0.77 & 0.77 \\
\hline & & (22.9\%) & $(77.3 \%)$ & (0.65 to 0.87 ) & (0.66 to 0.86 \\
\hline \multirow[t]{2}{*}{ Any of SOX1, PAX1 } & & 28 & 57 & 0.86 & 0.60 \\
\hline & & (38.9 \%) & (86.3 \%) & (0.76 to 0.94$)$ & (0.48 to 0.72$)$ \\
\hline \multirow[t]{2}{*}{ Any of SOX1, ZNF582 } & & 26 & 55 & 0.83 & 0.63 \\
\hline & & (36.1 \%) & (83.4 \%) & (0.72 to 0.91$)$ & (0.51 to 0.74 ) \\
\hline \multirow[t]{2}{*}{ Any of PAX1, ZNF582 } & & 28 & 59 & 0.89 & 0.60 \\
\hline & & (38.9\%) & (89.4 \%) & (0.79 to 0.96$)$ & (0.48 to 0.72$)$ \\
\hline \multirow[t]{2}{*}{ Any one of three } & & 35 & 62 & 0.94 & 0.50 \\
\hline & & $(50.0 \%)$ & (93.9\%) & (0.85 to 0.98$)$ & (0.38 to 0.62$)$ \\
\hline \multirow[t]{2}{*}{ Any two three } & & 12 & 47 & 0.71 & 0.83 \\
\hline & & $(17.1 \%)$ & $(71.2 \%)$ & (0.59 to 0.82$)$ & (0.72 to 0.91$)$ \\
\hline
\end{tabular}

CIN2 (including normal, CIN 1 and $\mathrm{CIN} 2$ ), $\mathrm{CIN}^{+}$including $\mathrm{CIN} 3, \mathrm{CIS}, \mathrm{SCC}, \mathrm{ASC}$ and $\mathrm{AC}$ ), CI confident interval

${ }^{a}$ The optimal cutoff value of methylation index is identified in the self-collected group 

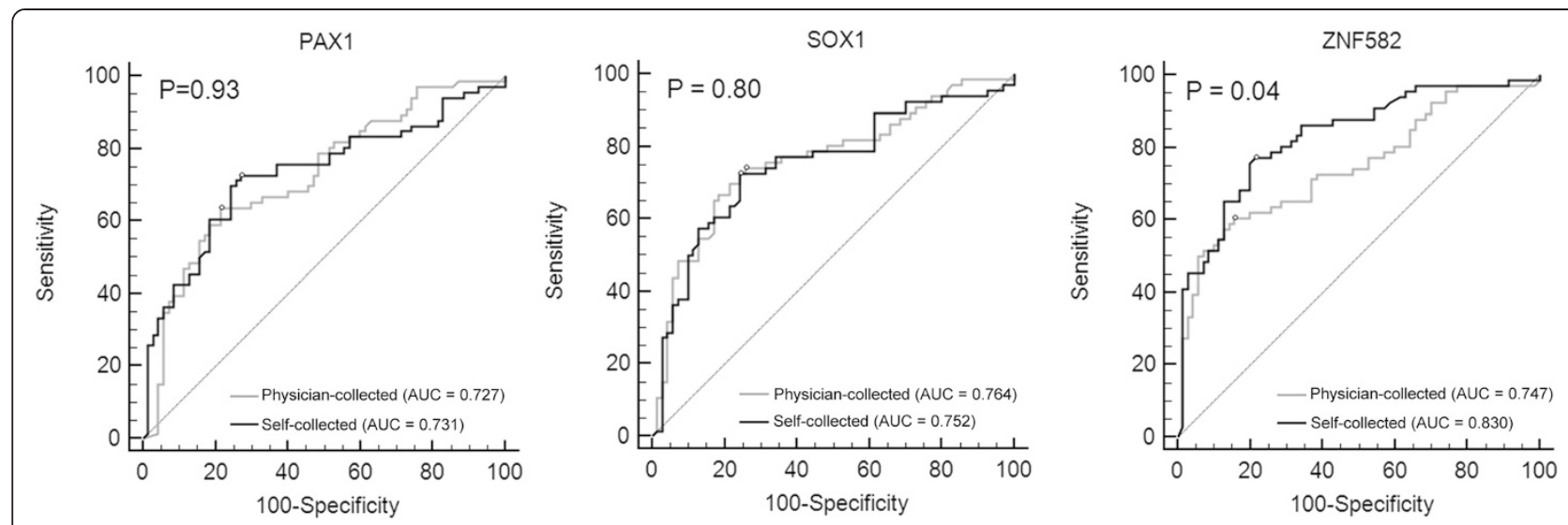

Fig. 3 Concordance in the clinical performance of methylation biomarkers between the self-collected and physician-collected groups. Receiver operating characteristic (ROC) curve analysis of PAX1, SOX1 and ZNF582. The area under curve (AUC) of the ROC curve of each gene was calculated for the diagnosis of CIN3 and further progressed (CIN3+) lesions. Differences with $P$-values less than 0.05 were considered to indicate statistical significance

among the women in the control group and few samples were obtained. In addition, this was a hospital-based study and so the results may not be representative of the general population. A standardized education program and userfriendly tools for self-collection are also warranted.

In developed countries with extensive infrastructure for conducting cytological examinations, Pap smears combined with methylation tests may perform better than a combination of Pap smears with HPV-testing in the detection of cervical neoplasm [28]. The reasons underlying the lack of participation in screening programs among women in developed countries are complex. Some examples of the barriers that have been reported are practical, such as appointment times and embarrassment [32]; therefore, creative and sensitive methods that take into consideration these barriers to participation in cervical cancer screening are required [32]. Self-collected sampling is time-saving and avoids embarrassment. For a non-attendee, self-collection of samples for molecular screening of hrHPV could be a suitable method for primary cervical cancer screening followed by cytology-based triage. Although the detection rate for CIN2+ or CIN3+ lesions is promising, cervical cytology sampling still requires intervention by a clinician $[21,23,24]$. Recent studies have used methylation biomarkers to triage patients who screened positive for hrHPV. The sensitivity of direct triage by combined analysis of the promoter methylation of miR-124-2 and the MAL genes in self-collected cervicovaginal material was similar to that of triage with cytological analysis of an additional physician-collected smear [20]. The search for complete methylation markers for use in triage of hrHPVpositive women or in primary screening of cervical cancer alone may further revolutionize cervical cancer screening.

Although self-collection of samples for hrHPV testing is an acceptable method screening for hrHPV infection, insufficient specificity will lead false-positive results in many patients in the absence of cervical neoplasm. Triage of these patients is required to confirm a true cervical intraepithelial neoplasm. Given the lack of infrastructure for conducting cytological examinations in low-resource areas, cytological screening is not ideal for triage; furthermore, the sensitivity of this method varies from $30 \%$ to $87 \%$ [33]. In contrast, only a few neoplastic cells are required for the detection of promoter methylation within a gene of interest using the QMSP assay. We determined that the highest sensitivity values for the detection of CIN3+ lesions by determining the methylation status of $P A X 1, S O X 1$, and ZNF582 in selfcollected samples was $0.73,0.73$, and 0.77 , respectively (Table 3). The clinical performance of this type of assay resembled that of a traditional cytological examination. The potential use of these new biomarkers as tools for cervical cancer screening as well as their possible use in the developing world to triage hrHPV-positive women during primary screening warrants further validation.

We used $\mathrm{CIN} 3+$ rather than $\mathrm{CIN} 2+$ as the cutoff in our study because of the equivocal nature of CIN2 lesions when diagnosed and the heterogeneity of their DNA methylation profiles $[17,34]$. While only $5 \%$ of CIN2 lesions progress to invasive cancer and approximately $40 \%$ regress, the corresponding percentages for CIN3 lesions are $33 \%$ and $12 \%$, respectively [35]. The pathology of CIN2 lesions is not clearly defined and these are the most difficult for pathologists to confirm among all Pap smear diagnoses [36, 37]. The clinical management of patients with CIN2 lesions should be reassessed using the most accurate techniques. The incorporation of molecular markers, such as DNA methylation profiles, into cervical cancer screening might help to decrease the number of unnecessary referrals and repeat diagnostic procedures, which are not only a drain 
on financial resources but also inflict an unnecessary burden on the patient. Additional studies are required to define the nature of CIN2 lesions with or without DNA methylation in longitudinal studies.

\section{Conclusions}

Our data confirm the reasonable to good concordance between DNA methylation biomarker profiles analyzed in self-collected and physician-collected samples for detection of CIN3+ lesions. This indicates that cervical cancer screening could be carried out not only on samples collected by physicians in a clinic setting, but also on self-collected vaginal samples. To confirm our results, the performance of our assay should be evaluated in prospective population-based clinical trials.

\footnotetext{
Abbreviations

PAX1: Paired box 1 gene; SOX1: Sex determining region Y-box 1; ZNF582: Zinc finger protein 582; CIN1: Cervical intraepithelial neoplasm I; CIN2: Cervical intraepithelial neoplasm II; CIN3: Cervical intraepithelial neoplasm III;

CIS: Carcinoma in situ; SCCs: Squamous cell carcinomas; ACs: Adenocarcinomas; ASCs: Adenosquamous carcinomas; AUC: Area under curve; QMSP: Quantitative methylation-specific polymerase chain reaction; HPV: Human papillomavirus; hrHPV: High-risk HPV.
}

\section{Competing interests}

The authors declare that they have no competing interests.

\section{Authors' contributions}

Conception and design of the experiments: C-CC, H-CL. Performance of the experiments: $\mathrm{H}-\mathrm{CW}, \mathrm{P}-\mathrm{HS}$ and $\mathrm{Y}-\mathrm{WH}$. Analyses of the data: R-LH. Contribution of reagents/materials/analysis tools: Y-PL, Y-WL. Drafting and editing of the manuscript: C-CC, R-L and HH-CL. Recruitment of participants and collection of clinical samples: C-CC, H-CL, C-YT, M-HY. All authors read and approved the final manuscript.

\section{Acknowledgements}

This work was supported in part by the following grants: Grants number: TSGH-C103-006-008-S01\&S02\&S03 from the Tri-Service General Hospital; NSC 102-2628-B-038-010-MY3 and NSC 103-2325-B-195-002 from Ministry of Science and Technology; 103TMU-SHH-11 and TMUTOP103005-1 from Taipei Medical University; the Teh-Tzer Study Group for Human Medical Research Foundation.

\section{Author details \\ ${ }^{1}$ Department of Obstetrics and Gynecology, Tri-Service General Hospital, National Defense Medical Center, Taipei, Taiwan, Republic of China. ${ }^{2}$ Graduate Institute of Medical Sciences, National Defense Medical Center, Taipei, Taiwan, Republic of China. ${ }^{3}$ Department of Obstetrics and Gynecology, Shuang Ho Hospital, Taipei Medical University, Taipei, Taiwan, Republic of China. ${ }^{4}$ Laboratory of Epigenetics and Cancer Stem Cells, National Defense Medical Center, Taipei, Taiwan, Republic of China. ${ }^{5}$ Graduate Institute of Life Sciences, National Defense Medical Center, Taipei, Taiwan, Republic of China. ${ }^{6}$ Department and Graduate Institute of Microbiology and Immunology, National Defense Medical Center, Taipei, Taiwan, Republic of China. ${ }^{7}$ Department of Obstetrics and Gynecology, School of Medicine, College of Medicine, Taipei Medical University, Taipei, Taiwan, Republic of China.}

\section{Received: 10 January 2015 Accepted: 30 April 2015}

\section{Published online: 19 May 2015}

\section{References}

1. Forouzanfar MH, Foreman KJ, Delossantos AM, Lozano R, Lopez AD, Murray CJ, et al. Breast and cervical cancer in 187 countries between 1980 and 2010: a systematic analysis. Lancet. 2011;378:1461-84.

2. Peto J, Gilham C, Fletcher O, Matthews FE. The cervical cancer epidemic that screening has prevented in the UK. Lancet. 2004;364:249-56.
3. Bos AB, Rebolj M, Habbema JD, van Ballegooijen M. Nonattendance is still the main limitation for the effectiveness of screening for cervical cancer in the Netherlands. Int J Cancer. 2006;119:2372-5.

4. de Bie RP, Vergers-Spooren HC, Massuger LF, Siebers AG, der Pol MR S-V, Vedder JE, et al. Patients with cervical cancer: why did screening not prevent these cases? Am J Obstet Gynecol. 2011;205(64):e61-7.

5. Zur Hausen H. Papillomaviruses and cancer: from basic studies to clinical application. Nat Rev Cancer. 2002;2:342-50.

6. Bosgraaf RP, Verhoef VM, Massuger LF, Siebers AG, Bulten J, de Kuyper-de Ridder GM, et al. Comparative performance of novel self-sampling methods in detecting high-risk human papillomavirus in 30,130 women not attending cervical screening. Int J Cancer J Int du cancer. 2014;136:646-55.

7. Lazcano-Ponce E, Lorincz AT, Cruz-Valdez A, Salmeron J, Uribe P, VelascoMondragon $E$, et al. Self-collection of vaginal specimens for human papillomavirus testing in cervical cancer prevention (MARCH): a community-based randomised controlled trial. Lancet. 2011;378:1868-73.

8. Virtanen A, Nieminen P, Luostarinen T, Anttila A. Self-sample HPV tests as an intervention for nonattendees of cervical cancer screening in Finland: a randomized trial. Cancer Epidemiol Biomarkers Prev. 2011;20:1960-9.

9. Zhao FH, Lewkowitz AK, Chen F, Lin MJ, Hu SY, Zhang X, et al. Pooled analysis of a self-sampling HPV DNA test as a cervical cancer primary screening method. J Natl Cancer Inst. 2012;104:178-88.

10. Szarewski A, Cadman L, Mesher D, Austin J, Ashdown-Barr L, Edwards R, et al. HPV self-sampling as an alternative strategy in non-attenders for cervical screening - a randomised controlled trial. Br J Cancer. 2011;104:915-20.

11. Snijders PJ, Verhoef VM, Arbyn M, Ogilvie G, Minozzi S, Banzi R, et al. High-risk HPV testing on self-sampled versus clinician-collected specimens: a review on the clinical accuracy and impact on population attendance in cervical cancer screening. Int J Cancer. 2013;132:2223-36.

12. Cuzick J, Clavel C, Petry KU, Meijer CJ, Hoyer H, Ratnam S, et al. Overview of the European and North American studies on HPV testing in primary cervical cancer screening. Int J Cancer. 2006;119:1095-101.

13. Rijkaart DC, Berkhof J, Rozendaal L, van Kemenade FJ, Bulkmans NW, Heideman DA, et al. Human papillomavirus testing for the detection of high-grade cervical intraepithelial neoplasia and cancer: final results of the POBASCAM randomised controlled trial. Lancet Oncol. 2012;13:78-88.

14. Garcia F, Barker B, Santos C, Brown EM, Nuno T, Giuliano A, et al. Cross-sectional study of patient- and physician-collected cervical cytology and human papillomavirus. Obstet Gynecol. 2003;102:266-72.

15. Farkas SA, Milutin-Gasperov N, Grce M, Nilsson TK. Genome-wide DNA methylation assay reveals novel candidate biomarker genes in cervical cancer. Epigenetics. 2013:8:1213-25.

16. Wentzensen N, Sherman ME, Schiffman M, Wang SS. Utility of methylation markers in cervical cancer early detection: appraisal of the state-of-the-science. Gynecol Oncol. 2009;112:293-9.

17. Lai HC, Lin YW, Huang RL, Chung MT, Wang HC, Liao YP, et al. Quantitative DNA methylation analysis detects cervical intraepithelial neoplasms type 3 and worse. Cancer. 2010;116:4266-74.

18. Huang RL, Chang CC, Su PH, Chen YC, Liao YP, Wang HC, et al. Methylomic analysis identifies frequent DNA methylation of zinc finger protein 582 (ZNF582) in cervical neoplasms. PLoS One. 2012;7:e41060.

19. Sova P, Feng Q, Geiss G, Wood T, Strauss R, Rudolf V, et al. Discovery of novel methylation biomarkers in cervical carcinoma by global demethylation and microarray analysis. Cancer Epidemiol Biomarkers Prev. 2006;15:114-23.

20. Verhoef VM, Bosgraaf RP, van Kemenade FJ, Rozendaal L, Heideman DA, Hesselink AT, et al. Triage by methylation-marker testing versus cytology in women who test HPV-positive on self-collected cervicovaginal specimens (PROHTECT-3): a randomised controlled non-inferiority trial. Lancet Oncol. 2014;15:315-22.

21. Hesselink AT, Heideman DA, Steenbergen RD, Coupe VM, Overmeer RM, Rijkaart D, et al. Combined promoter methylation analysis of CADM1 and MAL: an objective triage tool for high-risk human papillomavirus DNA-positive women. Clin Cancer Res. 2011;17:2459-65.

22. Overmeer RM, Louwers JA, Meijer CJ, van Kemenade FJ, Hesselink AT, Daalmeijer NF, et al. Combined CADM1 and MAL promoter methylation analysis to detect (pre-)malignant cervical lesions in high-risk HPV-positive women. Int J Cancer. 2011;129:2218-25.

23. Hansel A, Steinbach D, Greinke C, Schmitz M, Eiselt J, Scheungraber C, et al. A promising DNA methylation signature for the triage of high-risk human papillomavirus DNA-positive women. PLoS One. 2014;9:e91905. 
24. Eijsink JJ, Lendvai A, Deregowski V, Klip HG, Verpooten G, Dehaspe L, et al. A four-gene methylation marker panel as triage test in high-risk human papillomavirus positive patients. Int J Cancer. 2012;130:1861-9.

25. Lai HC, Lin YW, Huang TH, Yan P, Huang RL, Wang HC, et al. Identification of novel DNA methylation markers in cervical cancer. Int J Cancer. 2008;123:161-7.

26. Chang CC, Huang RL, Wang HC, Liao YP, Yu MH, Lai HC. High methylation rate of LMX1A, NKX6-1, PAX1, PTPRR, SOX1, and ZNF582 genes in cervical adenocarcinoma. Int J Gynecol Cancer. 2014;24:201-9.

27. Lin $\mathrm{H}$, Chen TC, Chang TC, Cheng YM, Chen CH, Chu TY, et al. Methylated ZNF582 gene as a marker for triage of women with Pap smear reporting low-grade squamous intraepithelial lesions - a Taiwanese Gynecologic Oncology Group (TGOG) study. Gynecol Oncol. 2014;135:64-8.

28. Lai HC, Ou YC, Chen TC, Huang HJ, Cheng YM, Chen $\mathrm{CH}$, et al. PAX1/SOX1 DNA methylation and cervical neoplasia detection: a Taiwanese Gynecologic Oncology Group (TGOG) study. Cancer medicine. 2014;3:1062-74.

29. Chu TY, Hwang KS, Yu MH, Lee HS, Lai HC, Liu JY. A research-based tumor tissue bank of gynecologic oncology: characteristics of nucleic acids extracted from normal and tumor tissues from different sites. Int J Gynecol Cancer. 2002;12:171-6.

30. Youden WJ. Index for rating diagnostic tests. Cancer. 1950;3:32-5.

31. Boers A, Bosgraaf RP, van Leeuwen RW, Schuuring E, Heideman DA, Massuger LF, et al. DNA methylation analysis in self-sampled brush material as a triage test in hrHPV-positive women. Br J Cancer. 2014;111:1095-101.

32. Waller J, Jackowska M, Marlow L, Wardle J. Exploring age differences in reasons for nonattendance for cervical screening: a qualitative study. BJOG. 2012;119:26-32.

33. Nanda K, McCrory DC, Myers ER, Bastian LA, Hasselblad V, Hickey JD, et al. Accuracy of the Papanicolaou test in screening for and follow-up of cervical cytologic abnormalities: a systematic review. Ann Intern Med. 2000;132:810-9.

34. Holowaty P, Miller AB, Rohan T, To T. Natural history of dysplasia of the uterine cervix. J Natl Cancer Inst. 1999;91:252-8.

35. Ostor AG. Natural history of cervical intraepithelial neoplasia: a critical review. Int J Gynecol Pathol. 1993;12:186-92.

36. Stoler MH, Schiffman M. Atypical Squamous Cells of Undetermined Significance-Low-grade Squamous Intraepithelial Lesion Triage Study G: Interobserver reproducibility of cervical cytologic and histologic interpretations: realistic estimates from the ASCUS-LSIL Triage Study. Jama. 2001;285:1500-5.

37. Carreon JD, Sherman ME, Guillen D, Solomon D, Herrero R, Jeronimo J, et al. CIN2 is a much less reproducible and less valid diagnosis than CIN3: results from a histological review of population-based cervical samples. Int J Gynecol Pathol. 2007;26:441-6.

\section{Submit your next manuscript to BioMed Central and take full advantage of:}

- Convenient online submission

- Thorough peer review

- No space constraints or color figure charges

- Immediate publication on acceptance

- Inclusion in PubMed, CAS, Scopus and Google Scholar

- Research which is freely available for redistribution 